\title{
AGING AND IMMUNE FUNCTION: CELLULAR AND BIOCHEMICAL ANALYSES
}

\author{
RichaRd A. Miller \\ Department of Pathology, University of Michigan Medical School, Institute of Gerontology, Ann Arbor \\ VA Medical Center, Ann Arbor, Michigan 48109
}

\begin{abstract}
Recent progress on the cellular and molecular basis for $\mathrm{T}$ cell dysfunction in aged mice is reviewed, with emphasis on defects in calcium signal generation and protein kinase function. The accumulation in older mice of memory $\mathrm{T}$ cells at the expense of naive $\mathrm{T}$ cells seems to account for most of the decline in the proportion of cells that can secrete or respond to interleukin 2. Memory $T$ cells in mice of any age have an intrinsic resistance to increases in cytoplasmic free calcium ion concentration, which in turn interferes with their responses to polyclonal activators. $T$ cells from old mice also exhibit declines both in serine/threonine and in tyrosine-specific protein kinase signals after activation by either receptor-dependent or receptorindependent agonists.
\end{abstract}

Key Words: immunology, calcium, protein kinase, memory $T$ cells, naive $T$ cells

\section{INTRODUCTION}

THE POPULATION of $T$ cells in aging mice can be viewed as a changing mosaic of cells with different activation requirements and functional competencies. Multiple lines of evidence have shown that the fraction of $T$ cells able to respond to commonly employed polyclonal activators in tissue culture declines with age. Thus, limiting dilution (LD) analyses reveal a decline in the proportion of $T$ cells that can respond to the plant lectin Con A by proliferation, by secretion of the growth factor interleukin 2 (IL-2), or by differentiation into a clone of cytotoxic effectors (Nordin and Collins, 1983; Miller, 1984). The proportion of $T$ cells able to generate a prompt intracellular calcium signal after treatment with Con $\mathrm{A}$ or antibody to the $\mathrm{CD} 3$ chain also declines with age (Miller et al., 1987; Grossmann et al., 1990), as does the fraction of cells that can express the p55 and p70 chains of the IL-2 receptor (Negoro et al., 1986; Vie and Miller, 1986; Hara et al., 1988). This review will focus on three related issues: 1) What is the developmental origin of the hyporesponsive T cell subset(s)? 2) What is the biochemical basis 
for the defect in calcium signal generation? 3) Could alterations in protein kinase signals contribute to the diminished responses of $\mathrm{T}$ cells from old mice?

\section{DEVELOPMENTAL BIOLOGY OF AGING T CELLS}

It is a plausible, though unproven, assumption that the dramatic involution of thymic mass and composition seen in old mice and humans is responsible for the accompanying loss of defensive immunity inducible in the peripheral tissues. In principle, the hyporesponsive $T$ cells that accumulate in aging mice might represent the final cohorts of peripheral cells generated by the involuting thymus, or alternately the residua of peripheral $\mathrm{T}$ cells produced by thymic traffic early in life and damaged by some effect of their relatively long survival in the peripheral tissues. Studies of $T$ cell heterogeneity in young mice have revealed differences in surface antigen expression between the "naive" $T$ cells that have emigrated recently from the thymus and the "memory" $T$ cells that have undergone one or more cycles of antigen-driven proliferation (Budd et al., 1987). Naive T cells express relatively high levels of the CD45RB isoform of the CD45 tyrosine-specific protein phosphatase, while memory cells express relatively high levels of CD44 (Budd et al., 1987; Lee and Vitetta, 1991). Surgical removal of the thymus gland leads within a few months to a dramatic reduction in the proportion of CD44 $4^{\text {lo }} \mathrm{T}$ cells at the expense of CD44 ${ }^{\text {hi }}$ cells (Budd et al., 1987), which is consistent with the idea that continued thymic emigration might be required in adult life to maintain a supply of fresh naive $T$ cells, and that thymic involution might indeed alter the balance of CD44 ${ }^{\text {lo }}$ to CD44 ${ }^{\text {hi }}$ cells. It thus seemed plausible that normal aging might be accompanied by a shift in the proportion of $T$ cells from naive to memory $T$ cell subsets.

We confirmed this idea using an antibody to CD44 (then known as PGP-1 for phagocyte glycoprotein 1) to quantitate memory and naive $T$ cells in peripheral tissues of young and old mice (Lerner et al., 1989). We found that memory T cells made up about $20 \%$ of the peripheral $\mathrm{T}$ cells in young mice, but roughly $50 \%$ of the population of $\mathrm{T}$ cells in older animals. This shift from naive to memory cells affected both the helper (CD4) and cytotoxic (CD8) subsets in blood, lymph node, and spleen, took place progressively between the 3rd and 24th month of life, and was demonstrable in at least two strains of long-lived $\mathrm{F}_{1}$ hybrids, $\mathrm{B} 6 \mathrm{D} 2 \mathrm{~F}_{1}$ (Lerner et al., 1989) and $\mathrm{B} \mathrm{CBAF} \mathrm{F}_{1}$ (Flurkey et al., 1992). Reciprocally, cells exhibiting the CD45RB ${ }^{\text {hi }}$ phenotype of naive cells decline with age in mice (Ernst et al., 1990; Flurkey et al., 1992) and humans (De Paoli et al., 1988; Serra et al., 1988; Walker et al., 1990; Pilarski et al., 1991).

Does this shift in subset distribution have functional consequences? We tested this notion using electronic cell sorting to examine the proportion of responsive $T$ cells within naive and memory subsets of mice of various ages. The results, shown in Fig. 1, demonstrate preferential responsiveness of cells in the naive $\left(C D 44^{\text {lo }}, C D 45 R^{\text {hi }}\right)$ subset, compared to memory $\mathrm{T}$ cells $\left(\mathrm{CD} 44^{\mathrm{hi}}, \mathrm{CD} 45 \mathrm{RB}^{\mathrm{lo}}\right)$. Responses to staphylococcal enterotoxin $B$ (SEB), a superantigen that, unlike Con $A$, is known to trigger $T$ cells through the $\mathrm{T}$ cell receptor, are similarly almost completely restricted to the naive subset, in both young and old mice. Production of both IL-2 and IL-3 seems, at least under these culture conditions, to reflect largely the function of the naive $\mathrm{T}$ cell subset, and the differences between young and old mice can thus be attributed to the relatively high proportion of naive cells in the $\mathrm{T}$ cells from the younger donors. Naive $\mathrm{T}$ cells from mice of any age seem about equally able to respond to these two activators under LD 
$\mathrm{IL}-2$
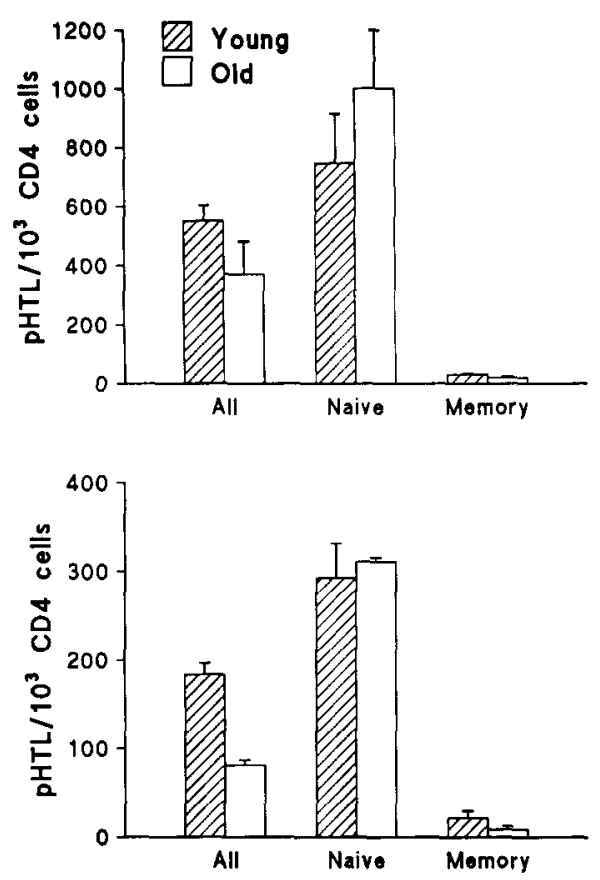

IL-3
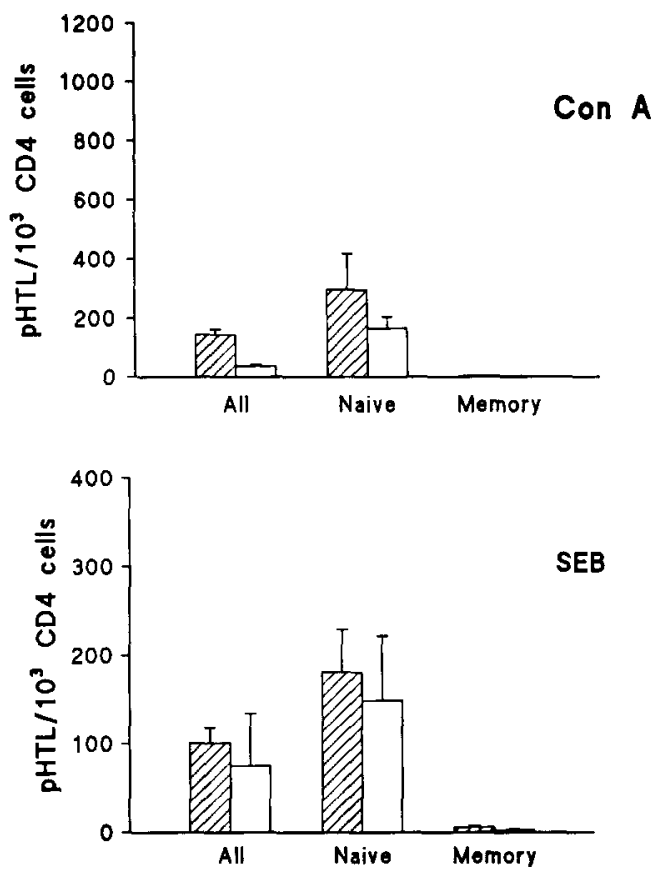

FIG. 1. Limit dilution analysis of lymphokine production by separated $\mathrm{T}$ cell subsets from young and old donors. Electronic cell sorting was used to produce naive (i.e., CD44 ${ }^{10}$ ) and memory (i.e., CD45RB ${ }^{10}$ ) $\mathrm{T}$ cells, which were stimulated with Con A (upper panels) or with staphylococcal enterotoxin B (SEB, lower panels); cultures were then assayed for production either of IL-2 (left panels) or IL-3 (right panels). Frequencies are expressed as a percentage of the number of $\mathrm{CD} 4$ cells present in the separated subsets. Values are means $\pm \mathrm{SE} ; N=3$ experiments. Data from Flurkey et al. (1992).

conditions. Though memory $\mathrm{T}$ cells are poorly responsive even when isolated from young mice, memory $\mathrm{T}$ cells from old mice are even less likely to respond.

It is important to realize that these data do not imply that memory $\mathrm{T}$ cells are less reactive than naive $\mathrm{T}$ cells under all stimulation conditions. Indeed, responses to cognate antigens, presented after appropriate digestion by antigen-presenting cells, are usually far stronger among memory than among naive $\mathrm{T}$ cells, and many groups have identified combinations of agonists that activate memory cells preferentially in high density cultures (Sanders et al., 1988; Horgan et al., 1990). Memory cells from young mice respond vigorously to previously encountered cognate antigens in LD cultures, too, showing that the weak responses of memory cells to Con A and SEB do not represent merely a technical limitation of the culture conditions (Flurkey et al., 1992). Much work needs to be done to produce a comprehensive model of how differences in stimuli, costimuli, and cellular interactions lead to activation of different $T$ cell subsets in specific circumstances. Our current data suggest, however, that the shift from naive to memory $T$ cell subsets may render the older animal less able to respond to classes of stimuli mimicked by Con A and SEB. 
These results also suggest an answer to the developmental question asked above: Poor responses of $\mathrm{T}$ cells from old mice seem, at least partially, to reflect the accumulation of memory cells from their naive precursors, rather than the emigration from the involuting thymus of new, flawed, naive cells. This picture of the aging immune system as a shifting mosaic of cell subsets may also hold some promise for the analysis of age-dependent changes among component cell subsets in other tissues ordinarily, but perhaps hastily, treated as homogeneous.

\section{CALCIUM HOMEOSTASIS IN T CELLS FROM AGING MICE}

The advent of calcium-sensitive intracellular fluorochromes (Grynkiewicz et al., 1985) has allowed many investigators to examine the effects of various agonists on intracellular calcium ion concentrations $\left([\mathrm{Ca}]_{\mathrm{i}}\right.$ ) in intact cells exposed to physiological agonists. Our early work (Miller et al., 1987) showed that when T cells from young or old mice were activated with Con $\mathrm{A},[\mathrm{Ca}]_{\mathrm{i}}$ increased to a greater extent in the cells from the young donors, and that this reflected a decline with age in the proportion of the $T$ cells that could increase $[\mathrm{Ca}]_{i}$ above the resting, baseline concentrations. Similar findings have been reported in two other studies of mouse T cells (Proust et al., 1987; Grossmann et al., 1990) and in one study of human T cells (Whisler et al., 1991), although in other work the effects of aging on human peripheral blood $\mathrm{T}$ cells have been less dramatic (Grossmann et al., 1989; Lustyik and O'Leary, 1989). These data show that the effects of aging on $T$ cell function can be detected within the first minute after activation, and raise a number of new questions: 1) Which of the several control mechanisms that regulate $[\mathrm{Ca}]_{\mathrm{i}}$ are altered by the aging process? 2) Does the inability to generate this signal account for the poor functional responses of $T$ cells, measured by proliferation, IL-2 production, and cytotoxicity? 3) Does the change in the proportion of cells able to produce a calcium signal reflect the accumulation of memory lymphocytes?

The first question has been addressed by analyses of three potential regulators of calcium concentration: release from intracellular stores by inositol trisphosphate $\left(\mathrm{IP}_{3}\right)$, influx from the extracellular medium, and ATP-dependent calcium extrusion from cytoplasm to medium. An alteration in $\mathrm{IP}_{3}$ production seemed unlikely to account for much of the change, since release of calcium from intracellular stores accounts for only a small proportion of the total change in $[\mathrm{Ca}]_{i}$ in normal $\mathrm{T}$ cells after activation by $\mathrm{Con}$ A (Gelfand et al., 1988). Furthermore, using two different assay methods, we found that Con A-induced production of both $\mathrm{IP}_{3}$ and its immediate metabolite $\mathrm{IP}_{4}$ proceeded at equal rates in $T$ cells from young and old mice (Lerner et al., 1988). A second group has reported contrasting results on $\mathrm{IP}_{3}$ production by $\mathrm{T}$ cells from old mice (Proust $e$ t al., 1987), but a third group has shown that human $T$ cells also seem not to exhibit an age-related loss in $\mathrm{IP}_{3}$ induction (Whisler et al., 1991), in agreement with our results.

The effect of age on calcium influx was tested in a study using ${ }^{45} \mathrm{Ca}$ as a radiotracer (Lerner et al., 1988). T cells from young and old mice were placed into a solution containing ${ }^{45} \mathrm{Ca}$ together with $\mathrm{Con} \mathrm{A}$, and samples taken $0,20,40$, and $60 \mathrm{~s}$ later were evaluated for cell-associated label. Uptake was found to be linear with time between 20 and $60 \mathrm{~s}$ after Con $\mathrm{A}$ addition, and thus the difference between cell ${ }^{45} \mathrm{Ca}$ at these two time points was calculated as an estimate of the rate of influx at steady state. The results (Fig. 2, left panel) show that Con A does indeed augment the rate at which calcium 


\section{Con A}

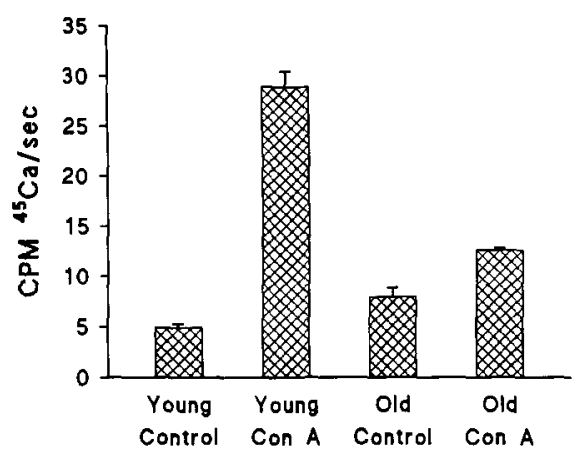

lonomycin

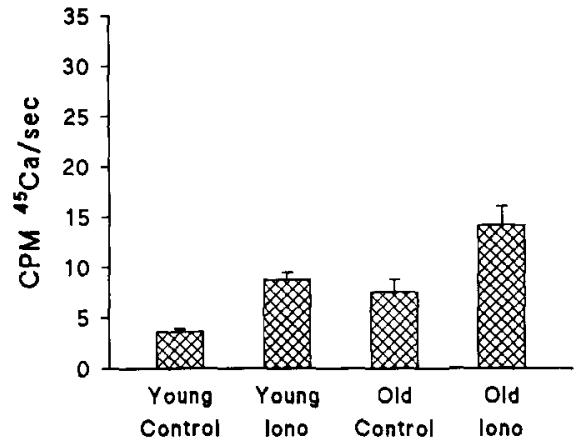

Fig. 2. Uptake of ${ }^{45} \mathrm{Ca}$ into $\mathrm{T}$ cells from young and old mice after exposure to either Con $\mathrm{A}$ (left panel) or ionomycin (right panel). Values given are means $\pm \mathrm{SE}$ for $N=5$ determinations, and represent the rate of increase in cell-associated ${ }^{45} \mathrm{Ca}$ between 20 and $60 \mathrm{~s}$ after agonist addition. From Lerner et al. (1988) and Miller et al. (1989).

enters the cell from the medium, and that this induction of influx is blunted by aging. The rate of calcium influx in the absence of mitogen is for unknown reasons consistently (and significantly) higher in $\mathrm{T}$ cells from old mice, but the difference between old and young $\mathrm{T}$ cells after Con A treatment is statistically significant whether calculated as total influx or the increase over the influx rate in unactivated controls.

Although these data provide further evidence for age-related defects in activation early in the activation cascade, it seems unlikely that the influx data alone can explain the effect of age on $[\mathrm{Ca}]_{i}$, since the mitogen-induced increase in calcium influx is quite transient, with influx rates falling back to baseline levels within 5 min (Freedman et al., 1975). In addition, comparison of the number of moles of calcium actually imported to the moles of calcium needed to account for the alteration in $[\mathrm{Ca}]_{\mathrm{i}}$ shows that at least $99 \%$ of the calcium imported does not end up in the pool of free calcium, but instead must be sequestered at some intracellular site or (more likely) returned to the medium through the activity of the plasma membrane pump. These considerations suggested to us that the difference in $[\mathrm{Ca}]_{\mathrm{i}}$ between old and young $\mathrm{T}$ cells, which is still easily demonstrable 5 min after mitogen addition, might reflect an alteration in the rate of calcium efflux rather than influx.

Radiotracer methods cannot accurately estimate the activity of the membrane calcium pump, since the large majority of calcium ions in tracer-labelled cells are sequestered in intracellular pools (mitochondrial, endosomal, or protein-bound), and estimates of release of radiocalcium from labelled cells thus reflect a complex mixture of fluxes among these intracellular pools and the free cytoplasmic pool to which the pump has access. To provide an indirect measure of the ability of the calcium pump to regulate $[\mathrm{Ca}]_{i}$, we devised an "ionomycin challenge" method, in which $[\mathrm{Ca}]_{i}$ levels are measured fluorimetrically in T cells exposed to very small doses of calcium ionophore. High doses of ionomycin bring calcium into the cell at rates above those for which the extrusion pump can compensate, but at lower doses the ionomycin-facilitated inward diffusion can be just compensated by pump-mediated extrusion, so that a new equlib- 
rium $[\mathrm{Ca}]_{\mathrm{i}}$ can be established (Miller et al., 1989). Since the equilibrium $[\mathrm{Ca}]_{\mathrm{i}}$ level was found to be sensitive to agents (like PMA) that are known to activate the plasma membrane calcium pump, and to agents (like calmodulin inhibitors) that inhibit pump function, we concluded that the ionomycin-perturbed equilibrium $[\mathrm{Ca}]_{i}$ gave a relative estimate of pump activity in the face of calcium influx.

Comparisons of $T$ cells from young and old mice (Fig. 3) showed that ionomycin consistently produced a greater increase in $[\mathrm{Ca}]_{\mathrm{i}}$ in $\mathrm{T}$ cells from young mice (Miller et al., 1989). Radiotracer studies established that the resistance of old $T$ cells to ionomycin-mediated calcium signals was not due to any decline in the rate of passage of ionomycin-calcium complexes into the $T$ cells; in fact, calcium influx into old $T$ cells was slightly higher than into young $T$ cells in the presence of ionomycin (Fig. 2, right panel). Taken together, these data indicate that $T$ cells from old mice are relatively well "buffered" against changes in calcium concentration. This resistance may help to account for the poor responses by old T cells to agents like Con $\mathrm{A}$ and $\alpha \mathrm{CD} 3$ antibody, which activate cells in part via an increase in $[\mathrm{Ca}]_{i}$. It is likely that this resistance to increases in $[\mathrm{Ca}]_{i}$ reflects an increase in the activity or sensitivity of the ATP-dependent plasma membrane calcium pump, but definitive evidence on this point is still lacking.

In summary, the relatively low production of calcium signals by $T$ cells from old mice seems to reflect principally a change in the ability to sequester or extrude calcium ions, perhaps augmented by a diminished ability to respond to activation by an increase in calcium influx. We next wished to determine whether the decline in calcium signal generation had functional implications. To do this we used an electronic flow sorter to separate $T$ cells on the basis of intracellular calcium concentrations within 5 min after addition of an activator, either Con $\mathrm{A}, \alpha \mathrm{CD} 3$, or ionomycin. Cells that exhibited an

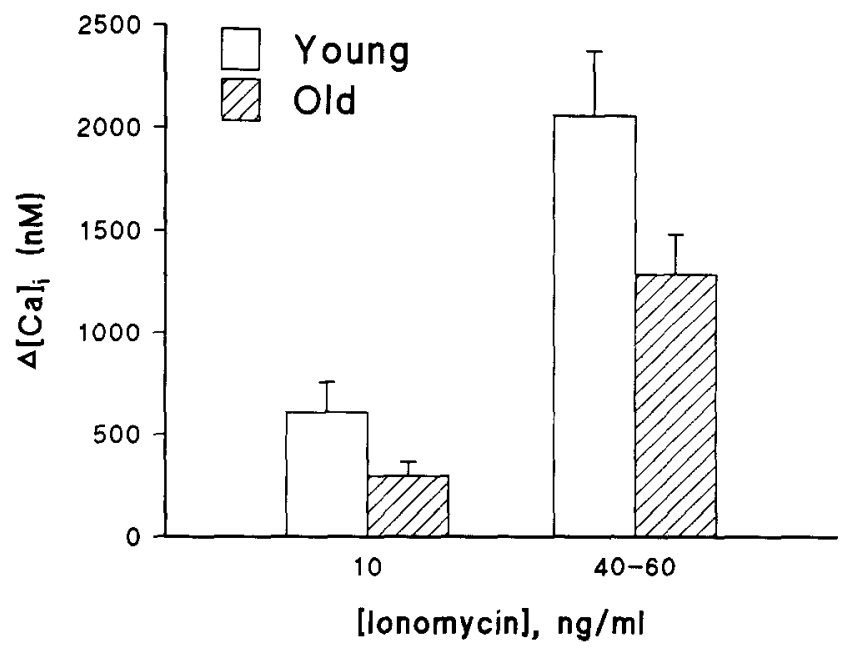

FIG. 3. Ionomycin-induced increases in $[\mathrm{Ca}]_{\mathrm{i}}$ are diminished in $\mathrm{T}$ cells from old mice. Calcium concentrations were measured using indo- 1 in $T$ cells before and at equilibrium (1-2 $\mathrm{min}$ ) after exposure to ionomycin at the indicated concentrations. Values represent the mean change in $[\mathrm{Ca}]_{\mathrm{i}} \pm \mathrm{SE} ; N=7$ experiments for $10 \mathrm{ng} / \mathrm{ml}$ and $N=8$ for $40-60 \mathrm{ng} / \mathrm{ml}$ ionomycin. The effect of age is significant at $p<0.02$ (two-tailed $t$-test) at each concentration of ionophore. Data summarized from Miller et al. (1989). 
increase in $[\mathrm{Ca}]_{i}$ were compared in LD assays to those that had not. Figure 4 shows results for a set of experiments using ionomycin to induce calcium signals. The subset of ionomycin-resistant cells (i.e., those that failed to produce a strong increase in $[\mathrm{Ca}]_{i}$ despite exposure to the ionophore) was found (Philosophe and Miller, 1989) to be severely depleted of cells able to produce IL-2 when compared either to unsorted cells or to cells selected for susceptibility to ionomycin. Similar differences between cells selected for or against calcium signal generation were obtained when the initial perturbation of calcium levels was induced either by Con A or by $\alpha \mathrm{CD} 3$ antibody rather than by ionomycin, and in experiments in which proliferation or cytotoxic function was measured along with helper function. The differences between ionomycin-suspectible and ionomycin-resistant cells were statistically significant for all three LD assays and for both young and old mice (Philosophe and Miller, 1989). We concluded from this study that generation of an early calcium signal was a critical part of the activation process for all three functional endpoints, and that the relative inability of $T$ cells from old mice to produce calcium signals after exposure to Con $\mathrm{A}$ or $\alpha \mathrm{CD} 3$ was thus likely to be a sufficient explanation for their inability to respond in LD cultures.

Finally, we wished to determine if the increase in calcium-buffered, functionally hyporeactive $\mathrm{T}$ cells in old mice reflected the switch from naive to memory pools. In a flow cytometric study (Philosophe and Miller, 1990) we measured calcium signals in T cells from old and young mice together with simultaneous discrimination of CD44 levels. We found that $\mathrm{CD} 44^{\mathrm{hi}}$ memory $\mathrm{T}$ cells in mice of any age generated smaller calcium responses in the presence of ionomycin than did naive T cells; both CD4 and CD8 $\mathrm{T}$ cells were equally affected. Memory cells were also found to be less likely than naive cells to generate a calcium signal after exposure to Con $\mathrm{A}$ or to $\alpha \mathrm{CD} 3$, although

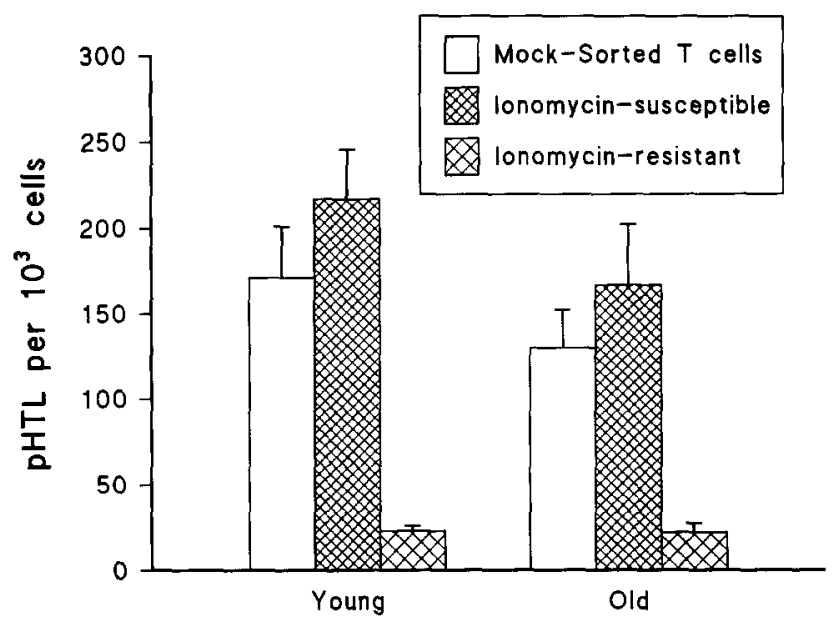

FIG. 4. Frequency of Con A-reactive, IL-2-producing pHTL cells in subsets selected for calcium signals after exposure to ionomycin. Ionomycin-susceptible cells were those that generated a relatively large increase in $[\mathrm{Ca}]_{\mathrm{i}}$ after $3 \mathrm{~min}$ of exposure to ionomycin; ionomycin-resistant cells exhibited a correspondingly small change in $[\mathrm{Ca}]_{\mathrm{i}}$. Mock-sorted controls were labelled and handled in the same way except that the calcium signal was ignored during the sorting process. Values are means $\pm S E$ for $N=10$ tests of young mice and $N=6$ tests of old mice. From Philosophe and Miller (1989). 
for these agents the differences were statistically significant only for the CD4 subpopulation. These data suggested that naive and memory $T$ cells were intrinsically distinct in their level of resistance to increases in $[\mathrm{Ca}]_{i}$, and that the accumulation of memory $T$ cells in old mice might indeed contribute to $T$ cell hyporesponsiveness.

A second approach has more recently provided further evidence in support of this idea (Miller et al., 1991). It had been noted (Ishida and Chused, 1988) that differences between $\mathrm{T}$ and $\mathrm{B}$ lymphocytes in calcium pump function led to differences in bouyant density after exposure to ionomycin: $\mathrm{T}$ cells from young mice were shown to respond to ionomycin treatment by an increase in $[\mathrm{Ca}]_{i}$, a consequent increase in calciumstimulated potassium efflux, and a decline in cell volume related to the potassium efflux. These authors had exploited this distinction to devise a method for separating normal young $\mathrm{T}$ and $\mathrm{B}$ cells on an ionomycin-containing Percoll density gradient. We reasoned that differences between naive and memory $\mathrm{T}$ cells in calcium pump function might also permit a similar separation of these two cell types. Indeed, the data (Miller et al., 1991) showed that Percoll/ionomycin gradients could be used to fractionate $T$ cells from young mice into distinct subsets. The denser cells (i.e., those expected to have increased their bouyant density as a consequence of calcium-induced efflux of potassium and water) were found as predicted to consist largely of naive $\mathrm{T}$ cells, while memory $\mathrm{T}$ cells were seen to be least susceptible to the ionomycin-induced increase in density. When Percoll/ionomycin-separated $\mathrm{T}$ cells were tested for responsiveness in LD cultures, the dense subfractions were found to be relatively enriched in Con A-reactive cells as detected in assays of IL-2 production and cytotoxic function. Responses to the superantigen SEB were also found to be much higher in the high density fraction than in the low density pools. Therefore this method provides independent support of the idea that calcium resistance, and a low frequency of Con A responsive cells, are characteristic of the memory $\mathrm{T}$ cell subset.

How rapidly do memory $T$ cells acquire calcium resistance? Is the resistance an intrinsic property of the memory cell state, or are memory $\mathrm{T}$ cells initially as likely to generate calcium signals as their naive precursors, with development of the resistance a gradual process? A study of mice infected with Schistosoma mansoni has provided some insight into this question (Miller et al., 1991). S. mansoni begin to produce highly immunogenic eggs about six weeks after infection. We therefore harvested spleen and lymph node cells from infected mice at week 8 (i.e., about two weeks after initial exposure to the egg antigens). As expected, the egg antigen-reactive $T$ cells were found to be CD45RB ${ }^{\text {lo }}$ and CD44 ${ }^{\text {hi }}$ (i.e., to express the surface antigens of memory T cells). Percoll/ionomycin separation showed that the egg antigen-responsive $\mathrm{T}$ cells were almost entirely localized in the low density (i.e., calcium resistant) fractions. These data suggest that memory $T$ cells acquire resistance to calcium signal generation within a period of a few days to a few weeks after acquisition of the memory cell phenotype.

In summary, aging leads to three linked changes in $T$ cell properties: a decline in the proportion of cells able to respond to strong polyclonal activators like Con $\mathrm{A}, \alpha \mathrm{CD} 3$, and SEB; a decline in the proportion of cells able to produce a calcium signal in responses to receptor-dependent or receptor-independent agents; and an increase in memory $\mathrm{T}$ cells at the expense of naive cells. These three transitions, however, are apparently not independent, but represent the gradual predominance, in old mice, of a cell type (the memory $\mathrm{T}$ cell) that is calcium-resistant and hyporeactive even in younger animals. 


\section{PROTEIN KINASE SIGNALS IN T CELLS FROM OLD MICE}

Activation of $\mathrm{T}$ lymphocytes is thought to depend upon signals mediated by at least two classes of protein kinases (i.e., those that phosphorylate serine and/or threonine residues and those that are tyrosine-specific). Our initial exploration of the question of kinase pathways in aging $\mathrm{T}$ cells used a two-dimensional electrophoretic system to survey mitogen-induced changes in major species of phosphorylated proteins (PPNs). A study using $T$ cells from young controls (Patel and Miller, 1991) established that $\alpha \mathrm{CD} 3$ antibody could induce dramatic (i.e., at least fourfold) increases in phosphorylation of a set of $16 \mathrm{PPN}$ substrates. Comparison of the responses to $\alpha \mathrm{CD} 3$ with responses induced by PMA (an activator of protein kinase $\mathrm{C}$ ) and by ionomycin, alone or in combination, allowed us to identify panels of "indicator" PPNs whose phosphorylation depended on induction of specific intracellular events.

Using this battery of indicator substrates we then proceeded to examine the effects of aging (Patel and Miller, 1992). Of the 16 PPNs that responded well to $\alpha C D 3$ in young $\mathrm{T}$ cells, all showed a dramatic decline in mice 22-24 months of age; none was inducible by more than 1.5 -fold in these older animals. The change was gradually progressive through adult life, with statistically significant changes as early as the 10th to 12th month of age, and further declines at 16-18 months and 22-24 months of age (Fig. 5). This synchrony implies that the decline in reactivity of this set of proteins may reflect an underlying age-sensitive regulatory process, such as an increase in phosphatase activity.

The possibility that the defect represents a simple failure of signal transduction

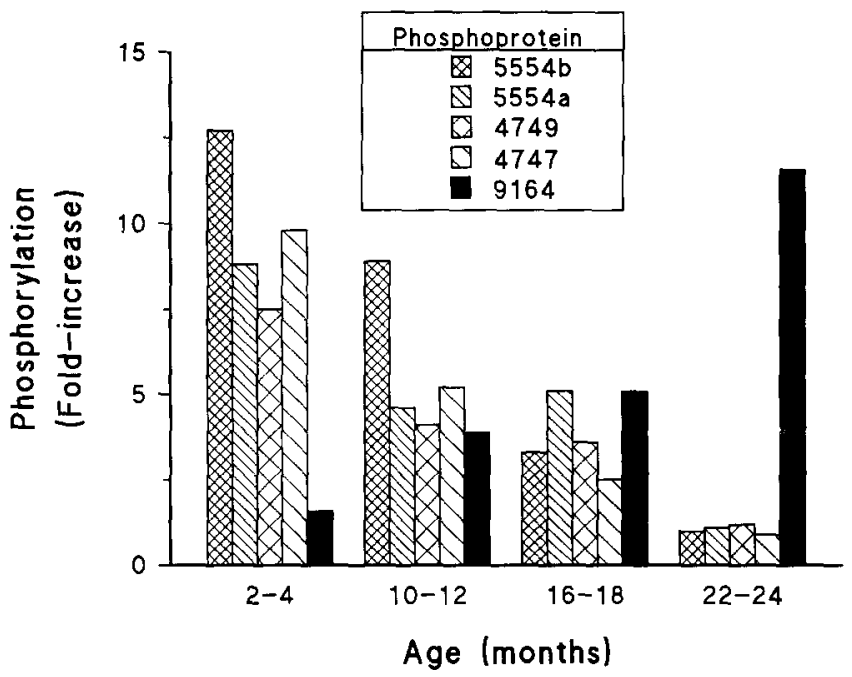

FIG. 5. Changes, with age, in anti-CD3 antibody-induced phosphorylation of five representative PPNs. Four of the PPNs show a progressive decline with age in response to anti-CD3, and are representative of 12 others that show similar declines. PPN 9164 shows an agedependent increase and is representative of two other PPNs with similar molecular weight and isoelectric point. Values are mean increases over the phosphorylation levels in lysates from unstimulated cells, and are derived from triplicate experiments; standard errors are not shown, but are less than $10 \%$ of the means in nearly all cases. From Patel and Miller (1992). 
through the CD3 proteins seems unlikely for two reasons. First, we found a group of three proteins, each of $91 \mathrm{kDa}$ molecular weight, which respond vigorously to $\alpha \mathrm{CD} 3$ stimulation only in $\mathrm{T}$ cells from older mice. Responses of this triplet increase gradually with age, in inverse relationship to the decline in responsiveness of the other 16 PPNs (see PPN 9164 in Fig. 5).

A second line of evidence comes from the analysis of responses to PMA and to ionomycin. Ten of the 12 proteins that responded to PMA in young mice were found to be nonreactive in old T cell preparations. Similarly, of the 10 PPNs found to respond in young mice to ionomycin treatment, all 10 were nonreactive in $\mathrm{T}$ cells from old mice. The poor responses to these intracellular agonists also argue against the hypothesis that a disorder in CD3-mediated transduction can by itself account for our results. The ionomycin and PMA data also raise additional questions. What accounts for the differences between the 10 PMA-reactive PPNs that fail to respond in old T cells and the pair that responds equally well in old as in young mice? (In this context it is worth noting that the three $91-\mathrm{kDa}$ PPNs that respond to $\alpha \mathrm{CD} 3$ in old but not in young mice are in old $T$ cells also fully responsive to PMA, though not to ionomycin.) In addition we need to determine the basis for the failure of ionomycin-dependent phosphorylation. We can rule out the suggestion that the ionomycin dose used was insufficient to raise $[\mathrm{Ca}]_{\mathrm{i}}$ concentrations appreciably, since ionomycin was found to inhibit one of the PMA-dependent phosphorylation responses equally well in old as in young mice. Identification of specific kinases, substrates, and phosphatases will be required to provide a clear picture of the underlying biochemistry.

The kinase studies also allowed us to identify PPN substrates whose phosphorylation proceeded only in specific T cell subsets. Several of the $\alpha \mathrm{CD} 3$-reactive PPNs were found to be nonresponsive in T cell preparations from which the CD8 subset had been removed, while others responded fully in CD4-enriched populations (Patel and Miller, 1991). Similarly, nine of the PPNs that responded well in the CD4-enriched pool were found not to respond after removal of the CD45RB ${ }^{\text {hi }}$ subset, suggesting that their activation was characteristic only of memory T cells (Patel and Miller, 1992). All of these subset-limited PPNs, however, were found to be equally hyporesponsive in unfractionated $\mathrm{T}$ cells prepared from old donors. Nor were the $91-\mathrm{kDa}$ proteins, characteristically responsive in old mice, found to be responsive in memory cell preparations from younger donors. We concluded therefore that the transition of naive to memory $\mathrm{T}$ cells could not account for the defects seen in protein phosphorylation, and that both the naive and memory $\mathrm{T}$ cell subsets in old mice were likely to be affected by similar alterations in kinase-dependent activation pathways.

\section{TYROSINE-SPECIFIC PROTEIN KINASE FUNCTION}

The majority of the PPNs examined by two-dimensional electrophoresis are presumably substrates for the serine/threonine kinases, which account for over $99 \%$ of total protein phosphorylation. Considerable evidence, however, has suggested that tyrosinespecific protein kinases (TPK) are critical to $T$ cell activation. To determine if aging affected these kinases, we used a Western blot method to measure TPK-mediated phosphorylation of specific substrates in resting and activated $T$ cells from young and old mice (Shi and Miller, 1992). Three tyrosine-phosphorylated phosphoproteins (PYPPN) were found to respond consistently to stimulation with $\alpha \mathrm{CD} 3$ and to Con $\mathrm{A}$, and 
two of these responded also to anti-T cell receptor antibody. Responses in all three PY-PPNs were maximal within 2 min after agonist addition, and remained high for 30 min. Results for reactions to $\alpha \mathrm{CD} 3$ are shown in Fig. 6. The differences between old and young mice were found to be statistically significant for all three substrates at 2, 5, and $10 \mathrm{~min}$ after activation. Responses in middle-aged mice (not shown) were found to be intermediate between those of young and old animals. We conclude that aging leads to a decline in at least some TPK-dependent phosphorylation pathways. Analysis of specific kinases and known substrates is now underway, as are studies of phosphorylation responses of separated subsets.

\section{CONCLUSIONS AND PROSPECTS}

A good deal of additional work remains to be done, and it would seem appropriate to end this review with an annotated list of selected suggestions for future investigation:

1. To what extent can immune dysfunction in aging humans be explained by alterations in $T$ cell subsets? Accumulation of $T$ cells with memory markers has been documented in aging humans (De Paoli et al., 1988; Serra et al., 1988; Walker et al., 1990; Pilarski et al., 1991), but the subset shifts have not yet been shown to contribute to the functional decline with age in human $\mathrm{T}$ cell function.

2. Do changes in calcium signal production also affect $T$ cells from old humans? Some reports (Grossmann et al., 1989; Lustyik and O'Leary, 1989), though not all (Whisler et al., 1991), suggest that this aspect of the activation process may not be an important factor in human immune senescence.

3. Which of the changes in calcium and kinase signals, if any, are linked to the mitogeninduced expression of activation genes? A decline in c-myc mRNA accumulation has been documented in $\mathrm{T}$ cells from old mice, and is suggested to reflect an alteration in processing of the initial transcript rather than an alteration in transcription rate per se (Buckler et al., 1988), but it is not yet clear if similar defects can be documented for other early activation genes, nor is it clear how these changes might result from gaps at earlier stages of the process.

4. Can the functional changes that cannot be explained by the shift from naive to memory subsets be attributed to shifts between cell types within these subsets? There is likely to be more heterogeneity among $\mathrm{T}$ cell types than has to date been quantifiable using the current crop of surface markers. The antibody $6 \mathrm{C} 10$, for example, allows discrimination of sets within the naive and memory populations of the mouse CD4 subset (Hayakawa and Hardy, 1989). We have also recently found that both naive and memory $T$ cells express varying levels of P-glycoprotein function, with the number of P-glycoprotein "high" cells increasing with age in both naive and memory subsets of CD4 and CD8 cells (Witkowski and Miller, 1993). It will be of interest to learn if differential expression of P-glycoprotein allows us to separate cells with different kinase pathways or functional responsiveness.

5. Several publications have recently suggested that the decline with age in $T$ cell production of IL-2 may be accompanied by an increase in the ability to secrete IL-4 (Ernst et al., 1990; Nagelkerken et al., 1991). Although IL-4 is thought to be produced principally by memory T cells in young donors (Bottomly et al., 1989; Lee et al., 1990), it is not clear whether memory $T$ cells from old mice will prove more able or less able to generate IL-4 than memory T cells from younger animals, and some 

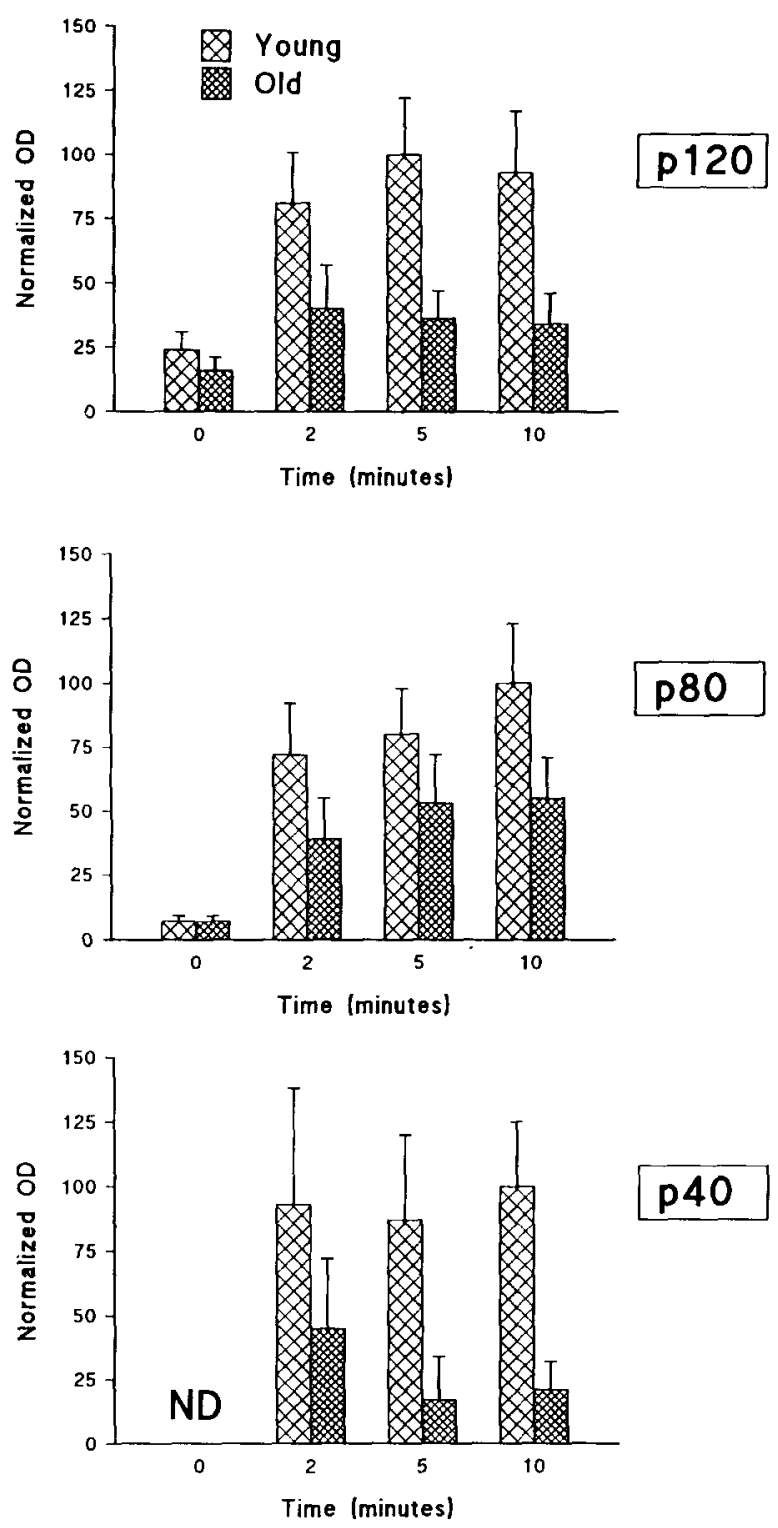

FIG. 6. Decline with age in tyrosine-specific phosphorylation of three PPNs by mouse $T$ cells in responses to anti-CD3 antibody. T cells were stimulated with anti-CD3 for 2, 5, or $10 \mathrm{~min}$, after which lysates were separated by polyacrylamide gel electrophoresis and PY-PPNs detected by Western blotting using antiphosphotyrosine antibody. Autoradiographs were quantitated by densitometry, and values normalized with respect to density of a 45-kDa PY-PPN that was found not to change with age or after stimulation. Values shown are means \pm SE for $N=9$ to 11 individual mice from each age group. The effect of age is statistically significant at $p<0.05$ or less at each time point and for each PY-PPN. From Shi and Miller (1992). 
culture conditions (Rocken et al., 1992) seem to induce vigorous IL-4 production from naive cells as well. Our own work (Li and Miller, unpublished) suggests that the relative amount of IL-4 produced by T cells from old and young mice depends critically on details of the culture system. Much more work is needed to determine how naive and memory $\mathrm{T}$ cells are induced to differentiate into IL-4 producers by combinations of stimuli and accessory signals, and to determine how these signals are altered by aging.

6. Lastly, it is by no means clear how the rate of immune senescence is timed in synchrony with the aging process itself. It is clear that retardation of aging by dietary restriction leads to a retardation of immune senescence, including the loss of functional T cells (Miller and Harrison, 1984) and the accumulation of memory cells (Miller, 1991). It is also clear that long-lived species (e.g., humans) remain immunocompetent far longer than short-lived ones. It is not clear whether members of a given species age at different rates, such that those individuals that exhibit especially rapid decline in immune function also show especially rapid decline in other agesensitive physiologic defences. It is equally uncertain to what extent immunosenescence leaves elderly people more vulnerable to infectious, neoplastic, and perhaps other degenerative illnesses. Carefully controlled longitudinal studies on genetically disparate subjects will be needed to address such issues; they are likely to be easier to do in mice than in humans.

Acknowledgments - Much of the work reviewed here was carried out by my students and colleagues, including Drs. Kevin Flurkey, Ben Philosophe, Adam Lerner, Hiren Patel, and Jia Shi, and was supported by grants from the National Institute on Aging and the American Federation for Aging Research.

\section{REFERENCES}

BOTTOMLY, K., LUQMAN, M., GREENBAUM, L., CARDING, S., WEST, J., PASQUALINI, T., and MURPHY, D.B. A monoclonal antibody to murine CD45R distinguishes CD4 $\mathrm{T}$ cell populations that produce different cytokines. Eur. J. Immunol. 19, 617-623, 1989.

BUCKLER, A., VIE, H., SONENSHEIN, G., and MILLER, R.A. Defective T lymphocytes in old mice: Diminished production of mature c-myc mRNA after mitogen exposure not attributable to alterations in transcription or RNA stability. J. Immunol. 140, 2442-2446, 1988.

BUDD, R.C., CEROTTINI, J.C., HORVATH, C., BRON, C., PEDRAZZINI, T., HOWE, R.C., and MACDONALD, H.R. Distinction of virgin and memory T lymphocytes. Stable acquisition of the Pgp-1 glycoprotein concomitant with antigenic stimulation. J. Immunol. 138, 3120-3129, 1987.

DE PAOLI, P., BATTISTIN, S., and SANTINI, G.F. Age-related changes in human lymphocyte subsets: Progressive reduction of the CD4 CD45R (suppressor inducer) population. Clin. Immunol. Immunopathol. 48, 290-296, 1988.

ERNST, D.N., HOBBS, M.V., TORBETT, B.E., GLASEBROOK, A.L., REHSE, M.A., BOTTOMLY, K., HAYAKAWA, K., HARDY, R.R., and WEIGLE, W.O. Differences in the expression profiles of CD45RB, Pgp-1, and 3G11 membrane antigens and in the patterns of lymphokine secretion by splenic CD4 + T cells from young and aged mice. J. Immunol. 145, 1295-1302, 1990.

FLURKEY, K., STADECKER, M., and MILLER, R.A. Memory T lymphocyte hyporesponsiveness to non-cognate stimuli: A key factor in age-related immunodeficiency. Eur. J. Immunol. 22, 931-935, 1992.

FREEDMAN, M.H., RAFF, M.C., and GOMPERTS, B. Induction of increased calcium uptake in mouse T lymphocytes by concanavalin A and its modulation by cyclic nucleotides. Nature 255, 378-382, 1975 .

GELFAND, E.W., CHEUNG, R.T., MILLS, G.B., and GRINSTEIN, S. Uptake of extracellular $\mathrm{Ca}^{2+}$ and not recruitment from internal stores is essential for $\mathrm{T}$ lymphocyte proliferation. Eur. J. Immunol. 18, 917-922, 1988.

GROSSMANN, A., LEDBETTER, J.A., and RABINOVITCH, P.S. Reduced proliferation in T lympho- 
cytes in aged humans is predominantly in the CD8 + subset, and is unrelated to defects in transmembrane signaling which are predominantly in the CD4+ subset. Exp. Cell Res. 180, 367-382, 1989.

GROSSMANN, A., LEDBETTER, J.A., and RABINOVITCH, P.S. Aging-related deficiency in intracellular calcium response to anti-CD3 or concanavalin A in murine T-cell subsets. J. Gerontol. Biol. Sci. 45, B81-B86, 1990.

GRYNKIEWICZ, G., POENIE, M., and TSIEN, R.Y. A new generation of $\mathrm{Ca}^{2+}$ indicators with greatly improved fluorescence properties. J. Biol. Chem. 260, 3440-3448, 1985.

HARA, H., TANAKA, T., NEGORO, S., DEGUCHI, Y., NISHIO, S., SAIKI, O., and KISHIMOTO, S. Age-related changes of expression of IL-2 receptor subunits and kinetics of IL-2 internalization in T cells after mitogenic stimulation. Mech. Ageing Dev. 45, 167-175, 1988.

HAYAKAWA, K. and HARDY, R.R. Phenotypic and functional alteration of CD4 + T cells after antigenic stimulation. Resolution of two populations of memory T cells that both secrete Interleukin 4. J. Exp. Med. 169, 2245-2250, 1989.

HORGAN, K.J., VAN SEVENTER, G.A., SHIMIZU, Y., and SHAW, S. Hyporesponsiveness of "naive" (CD45RA +) human $\mathrm{T}$ cells to multiple receptor-mediated stimuli but augmentation of responses by costimuli. Eur. J. Immunol. 20, 1111-1118, 1990.

ISHIDA, Y. and CHUSED, T.M. Heterogeneity of lymphocyte calcium metabolism is caused by T cellspecific calcium-sensitive potassium channel and sensitivity of the calcium ATPase pump to membrane potential. J. Exp. Med. 168, 839-852, 1988.

LEE, W.T. and VITETTA, E.S. The differential expression of homing and adhesion molecules on virgin and memory $\mathrm{T}$ cells in the mouse. Cell Immunol. 132, 215-222, 1991.

LEE, W.T., YIN, X.M., and VITETTA, E.S. Functional and ontogenetic analysis of murine CD45R ${ }^{\text {hi }}$ and CD45R ${ }^{\text {lo }}$ CD4 + T cells. J. Immunol. 144, 3288-3295, 1990.

LERNER, A., PHILOSOPHE, B., and MILLER, R.A. Defective calcium influx and preserved inositol phosphate generation in T cells from old mice. Aging Immunol. Infect. Dis. 1, 149-157, 1988.

LERNER, A., YAMADA, T., and MILLER, R.A. PGP- ${ }^{\text {hi }}$ T lymphocytes accumulate with age in mice and respond poorly to Concanavalin A. Eur. J. Immunol. 19, 977-982, 1989.

LUSTYIK, G, and O'LEARY, J.J. Aging and intracellular free calcium response in human T cells after stimulation by phytohemagglutinin. J. Gerontol. 44, B30-B36, 1989.

MILLER, R.A. Age-associated decline in precursor frequency for different T cell-mediated reactions, with preservation of helper or cytotoxic effect per precursor cell. $J$. Immunol. 132, 63-68, 1984.

MILLER, R.A. Caloric restriction and immune function: Developmental mechanisms. Aging Clin. Exp. Res. 3, 395-398, 1991.

MILLER, R.A., FLURKEY, K., MOLLOY, M., LUBY, T., and STADECKER, M.J. Differential sensitivity of virgin and memory $\mathrm{T}$ lymphocytes to calcium ionophores suggests a bouyant density separation method and a model for memory cell hyporesponsiveness to Con A. J. Immunol. 147, 3080-3086, 1991.

MILLER, R.A. and HARRISON, D.E. Delayed reduction in T cell precursor frequencies accompanies diet-induced lifespan extension. J. Immunol. 136, 977-983, 1984.

MILLER, R.A., JACOBSON, B., WEIL, G., and SIMONS, E.R. Diminished calcium influx in lectinstimulated T cells from old mice. J. Cell. Physiol. 132, 337-342, 1987.

MILLER, R.A., PHILOSOPHE, B., GINIS, I., WEIL, G., and JACOBSON, B. Defective control of cytoplasmic calcium concentration in T lymphocytes from old mice. J. Cell. Physiol. 138, 175-182, 1989.

NAGELKERKEN, L., HERTOGH-HUIJBREGTS, A., DOBBER, R., and DRAGER, A. Age-related changes in lymphokine production related to a decreased number of CD45RB ${ }^{\text {hi }} \mathrm{CD} 4+\mathrm{T}$ cells. Eur. $J$. Immunol. 21, 273-281, 1991.

NEGORO, S., HARA, H., MIYATA, S., SAIKI, O., TANAKA, T., YOSHIZAKI, K., IGARASHI, T., and KISHIMOTO, S. Mechanisms of age-related decline in antigen-specific T cell proliferative response: IL-2 receptor expression and recombinant IL-2 induced proliferative response of purified TAC-positive T cells. Mech. Ageing Dev. 36, 223-241, 1986.

NORDIN, A.A. and COLLINS, G.D. Limiting dilution analysis of alloreactive cytotoxic precursor cells in aging mice. J. Immunol. 131, 2215-2218, 1983.

PATEL, H.R. and MILLER, R.A. Analysis of protein phosphorylation patterns reveals unanticipated complexity in T lymphocyte activation pathways. J. Immunol. 146, 3332-3339, 1991.

PATEL, H.R. and MILLER, R.A. Age-associated changes in mitogen-induced protein phosphorylation in murine T lymphocytes. Eur. J. Immunol. 22, 253-260, 1992. 
PHILOSOPHE, B. and MILLER, R.A. T lymphocyte heterogeneity in old and young mice: Functional defects in T cells selected for poor calcium signal generation. Eur. J. Immunol. 19, 695-699, 1989.

PHILOSOPHE, B. and MILLER, R.A. Diminished calcium signal generation in subsets of T lymphocytes that predominate in old mice. J. Gerontol. Biol. Sci. 45, B87-B93, 1990.

PILARSKI, L.M., YACYSHYN, B.R., JENSEN, G.S., PRUSKI, E., and PABST, H.F. $\beta 1$ integrin (CD29) expression on human postnatal $\mathrm{T}$ cell subsets defined by selective CD45 isoform expression. J. Immunol. 147, 830-837, 1991.

PROUST, J.J., FILBURN, C.R., HARRISON, S.A., BUCHHOLZ, M.A., and NORDIN, A.A. Age-related defect in signal transduction during lectin activation of murine T lymphocytes. J. Immunol. 139, 1472-1478, 1987.

ROCKEN, M., MULLER, K.M., SAURAT, J.-H., MULLER, I., LOUIS, J.A., CEROTTINI, J.-C., and HAUSER, C. Central role for TCR/CD3 ligation in the differentiation of CD4 + T cells toward a Th1 or Th2 functional phenotype. J. Immunol. 148, 47-54, 1992.

SANDERS, M.E., MAKGOBA, M.W., and SHAW, S. Human naive and memory T cells: Reinterpretation of helper-inducer and suppressor-inducer subsets. Immunol. Today 9, 195-199, 1988.

SERRA, H.M., KROWKA, J.F., LEDBETTER, J.A., and PILARSKI, L.M. Loss of CD45R (Lp220) represents a post-thymic $T$ cell differentiation event. J. Immunol. 140, 1435-1441, 1988.

SHI, J. and MILLER, R.A. Tyrosine-specific protein phosphorylation in response to anti-CD3 antibody is diminished in old mice. J. Gerontol. Biol. Sci, 47, B147-B153, 1992.

VIE, $H$. and MILLER, R.A. Decline, with age, in the proportion of mouse T cells that express IL-2 receptors after mitogen stimulation. Mech. Ageing Dev. 33, 313-322, 1986.

WALKER, D., GAUCHAT, J.F., DE WECK, A.L., and STADLER, B.M. Analysis of leukocyte markers in elderly individuals. Aging Immunol, Infect. Dis. 2, 31-43, 1990.

WHISLER, R.L., NEWHOUSE, Y.G., DONNERBERG, R.L., and TOBIN, C.M. Characterization of intracellular ionized calcium responsiveness and inositol phosphate production among resting and stimulated peripheral blood T cells from elderly humans. Aging Immunol. Infect. Dis. 3, 27-36, 1991.

WITKOWSKI, J.M., and MILLER, R.A. Increased function of P-glycoprotein in T lymphocyte subsets of aging mice. J. Immunol. 150, 1296-1306, 1993. 